\section{Discussion}

Carbenicillin is an established antibiotic for infections due to two difficult groups of organisms-Ps. aeruginosa and the indolepositive Proteus spp. ${ }^{4}$ Non- $\beta$-lactamase-producing $E$. coli are very susceptible to carbenicillin and Str. faecalis moderately so. Though carbenicillin is particularly useful against Ps. aeruginosa high parenteral doses (up to $30 \mathrm{~g} /$ day) may be needed to treat systemic infections with this organism. High urinary concentrations of carbenicillin have been reported, ${ }^{5}$ with intramuscular doses of $500 \mathrm{mg}$ giving concentrations greater than $500 \mathrm{mg} / \mathrm{l}$. Such levels will eradicate sensitive $P$ s. aeruginosa (M.I.C. $\leqslant 100$ $\mathrm{mg} / \mathrm{l}$ ) but the injections are often painful and the patient usually needs to be in hospital.

Serum levels in volunteers and patients after oral carfecillin were found to be insufficient to treat systemic infection with Ps. aeruginosa, even when renal function was impaired, but urinary levels were sufficient to suggest that urinary infections might be eradicated.

In severe renal failure the mean serum half life of carbenicillin is only $10-20$ hours, $^{2}$ which is short compared with that of gentamicin (40-60 hours $\left.{ }^{6}\right)$ in similar patients. This suggests that there is a relatively rapid rate of decay of antipseudomonal activity in vivo or an extrarenal pathway of elimination or both. Berrill et al, ${ }^{7}$ using the indanyl ester of carbenicillin, thought that gastrointestinal absorption of the drug might be impaired in renal failure and adduced lower serum levels as evidence. They could not exclude increased extrarenal excretion, and our patients and volunteers with renal impairment tended to have higher serum levels than those with normal renal function.

The incidence of undesirable side effects with carfecillin compares favourably with that of indanyl ester of carbenicillin, which is also orally absorbed. Berrill et al. ${ }^{7}$ treated eight patients with the latter drug and stopped treatment in two because of rashes. Two others had diarrhoea. Wallace et al. ${ }^{8}$ reported 38 side effects in 26 patients, and treatment in three patients had to be stopped. In a double-blind series $^{\circ}$ eight patients out of 20 receiving carbenicillin indanyl sodium suffered side effects and the drug was withdrawn from one of these who had severe vomiting. Lees and Harding ${ }^{10}$ noted that $10.5 \%$ of patients who were given carfecillin capsules had diarrhoea, but only $4.35 \%$ who received the tablet form (as now marketed) complained of this side effect.

Our results compare favourably with those of Berrill et al, ? particularly as our dose was lower and given for seven days instead of 14. Our patients also had a high prevalence of urinary tract abnormalities. The overall cure rate with indanyl carbenicillin in the series of Ries et al. ${ }^{9}$ was $50 \%$ as compared with $60 \%$ in our series, though no pseudomonas infections were treated with indanyl carbenicillin in the former series as compared with 12 in ours.

Ps. aeruginosa rarely causes primary, uncomplicated urinary tract infection but it may cause infection secondary to other urinary tract conditions or operations where catheterization may have been necessary. ${ }^{11}$ The only antibiotic therapy available to such patients is by the parenteral route, which usually means a stay in hospital. The availability of a well-tolerated oral agent for such cases represents a therapeutic advance. Further studies with carfecillin are necessary, and possibly a longer course of treatment should be given in difficult cases, but this drug promises to be a useful oral treatment of urinary infections when the choice of effective antibiotics is limited.

The formulation of carfecillin to be marketed in the United Kingdom will differ slightly from that used in our studies reported here, the main change being improved oral absorption. ${ }^{3}$ Its performance in curing infection will probably be at least as good as that of the previous formulation, but side effects and tolerability will need to be reassessed.

We thank Mr. M. J. Bywater, Mr. H. A. Holt, and Mrs. H. D. Bennett for technical help; Dr. E. A. P. Croydon of Beecham Pharmaceuticals for providing the carfecillin and for helpful advice; and our clinical colleagues whose patients we treated.

\section{References}

1 Rolinson, G. N., personal communication, 1973.

${ }^{2}$ Eastwood, J. B., and Curtis, J. R., British Medical fournal, 1968, 1, 486.

3 Jones, K. H., personal communication, 1974

4 Brumfitt, W., Percival, A., and Leigh, D. A., Lancet, 1967, 1, 1289.

Meyers, B. R., Sabbaj, J., and Weinstein, L., Archives of Internal Medicine, $1970,125,282$.

${ }^{6}$ Gingell, J. C., and Waterworth, P. M., British Medical fournal, 1968, 2 , 19.

${ }^{2}$ Berrill, W. T., et al., British fournal of Urology, 1973, 45, 563.

${ }^{8}$ Wallace, J. F., et al., Antimicrobial Agents and Chemotherapy: Proceedings of the 10th Conference, 1970, p. 223. Bethesda, American Society for Microbiology, 1971.

9 Ries, K. M., et al., Antimicrobial Agents and Chemotherapy, 1973, 4, 593. ${ }^{10}$ Lees, L. J., and Harding, J. M., British Fournal of Clinical Practice, 1974,

11 Gould, J. C., in Urinary Tract Infection, ed. F. O'Grady and W. Brumfitt, p. 43. London, Oxford University Press, 1968.

\title{
Recovery from Goodpasture's Syndrome after Immunosuppressive Treatment and Plasmapheresis
}

\author{
C. M. LOCKWOOD, J. M. BOULTON-JONES, R. M. LOWENTHAL， I. J. SIMPSON, \\ D. K. PETERS, C. B. WILSON
}

British Medical fournal, 1975, 2, 252-254

\section{Summary}

A patient with Goodpasture's syndrome has recovered after treatment with immunosuppressive drugs (cyclo-

Renal Unit, Hammersmith Hospital, Royal Postgraduate Medical School, London W12 0HS

C. M. LOCKWOOD, M.R.C.P., Registrar

J. M. BOULTON-JONES, M.R.C.P., Senior Registrar

R. M. LOWENTHAL, M.B. M.R.C.P., Research Fellow

I. J. SIMPSON, M.R.A.C.P., Research Fellow

D. K. PETERS, M.R.C.P., Reader in Medicine

Department of Immunopathology, Scripps Clinic and Research Foundation, La Jolla, California

C. B. WILSON, M.D., Associate Member of Department phosphamide and prednisolone) and removal of circulating antibodies by plasma exchange. This was performed on seven occasions and seems to have hastened the decline in circulating antibody levels. Undertaken early in the course of the disease plasmapheresis could prove a useful addition to its therapy.

\section{Introduction}

Renal injury in most patients with Goodpasture's syndrome is known to be mediated by antibodies directed at the glomerular basement membrance (G.B.M.). ${ }^{1-3}$ This syndrome-the association of lung haemorrhage and glomerulonephritis-is characterized by a rapidly fatal course terminating in renal failure or asphyxia from uncontrolled lung haemorrhage. Since 
damage to the kidney and probably also to the lungs is mediated by antibody to their basement membranes ${ }^{3}$ immunosuppressive therapy with steroids and cytotoxic drugs seems logical but has generally been ineffective. We report here a patient in whom the combination of prednisolone and cyclophosphamide aimed at reducing antibody synthesis with plasmapheresis to remove circulating antibody was followed by reduction in circulating anti-G.B.M. antibody levels and substantial recovery from renal failure.

\section{Case Report}

A 24-year-old man had been well until June 1974, when he was referred to hospital with a three-week history of streaky haemoptyses. $\mathrm{He}$ had had no exposure to drugs or toxic solvents. Apart from pallor and an apical systolic murmur physical examination showed nothing abnormal. Investigations showed: haemoglobin $8 \mathrm{~g} / \mathrm{dl}$, W.B.C. $8 \times 10^{9} / 1$, serum iron $3.0 \mu \mathrm{mol} / 1(17 \mu \mathrm{g} / 100 \mathrm{ml})$, serum iron binding capacity $81.8 \mu \mathrm{mol} / 1(457 \mu \mathrm{g} / 100 \mathrm{ml})$, E.S.R. $25 \mathrm{~mm}$ in the first hour, blood urea $4.3 \mathrm{mmol} / 1(26 \mathrm{mg} / 100 \mathrm{ml})$, creatinine $79.6 \mu \mathrm{mol} / 1(0.9 \mathrm{mg}$ $100 \mathrm{ml}$ ), and creatinine clearance $66 \mathrm{ml} / \mathrm{min}$. Urine examination showed only occasional red cells and a trace of protein. Numerous haemosiderin-laden macrophages were found in the sputum on several occasions. Chest radiographs were normal. A renal biposy was performed, which on light microscopy showed 10 glomeruli. These were mostly normal but in two there was segmental proliferation with crescent formation and evidence of destruction of G.B.M. The tubules appeared normal. Immunofluorescence showed linear deposition of IgG along the G.B.M. Staining was strong and uniform in all glomeruli. Stains for IgA and C3 were only dubiously above background. IgM was present only as occasional flecks, and fibrin was confined to a crescent. Treatment was started with prednisolone $60 \mathrm{mg} /$ day on 7 August and reduced to $40 \mathrm{mg} /$ day on 15 August.

The patient was transferred to Hammersmith Hospital on 22 August, when his blood urea had risen to $18.3 \mathrm{mmol} / 1(110 \mathrm{mg} / 100 \mathrm{ml})$ and serum creatinine to $274 \mu \mathrm{mol} / 1(3.1 \mathrm{mg} / 100 \mathrm{ml})$. Creatinine clearance had fallen to $17 \mathrm{ml} / \mathrm{min}$ and the 24 -hour urinary protein excretion was $4.2 \mathrm{~g}$. Urine microscopy showed many red cells and occasional granular casts. Prednisolone was increased to $60 \mathrm{mg} /$ day and cyclophosphamide $3 \mathrm{mg} \mathrm{kg}^{-1} \mathrm{day}^{-1}$ added. Aspirin $300 \mathrm{mg} /$ day was also given to inhibit platelet stickiness. Heparin, 10000 units every six hours intravenously, was given for seven days from 29 August. An arteriovenous silastic shunt was inserted and used both for haemodialysis and plasmapheresis. This procedure was carried out seven times over 25 days beginning on 6 September.

Initially renal function showed steady deterioration so that peritoneal dialysis and haemodialysis became necessary (see fig.). There was no overt haemoptysis after the first week of steroid therapy but twice there were sudden falls in haemoglobin of about $4 \mathrm{~g}$ over 48 hours not associated with symptoms or overt signs of blood loss. After the first such fall a chest $x$-ray picture showed bilateral pulmonary infiltrates which cleared after six days. A second renal biopsy, which showed five glomeruli, was performed on 17 September. One of the glomeruli was normal but the others showed crescents and in two the capillary lumina were obliterated. There was some tubular atrophy and interstitial fibrosis. Findings on immunofluorescence were

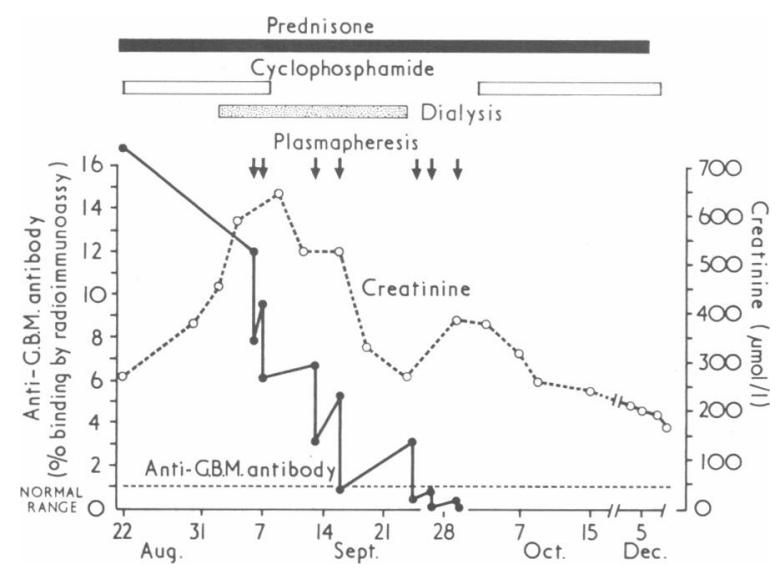

Levels of creatinine and anti-G.B.M. antibody before and during treatment. unchanged. After 18 days and five plasma exchanges renal function improved and dialysis was discontinued. Plasmapheresis was undertaken twice more. Renal function continued to improve and by March 1975 the serum creatinine was $141 \mu \mathrm{mol} / 1(1.6 \mathrm{mg} / 100 \mathrm{ml})$ with a clearance of $57 \mathrm{ml} / \mathrm{min}$.

\section{METHODS}

Renal tissue was obtained by percutaneous needle biopsy and specimens were processed for light microscopy by conventional techniques. Tissue for immunofluorescent studies was processed as described previously. ${ }^{4}$

Anti-G.B.M. antibody was measured using radiolabelled collagenase-solublized human G.B.M. in a double antibody radioimmunoassay. ${ }^{5}$ The results are expressed as percentage binding of the radiolabelled antigen: this is less than $1 \%$ in patients without other evidence of anti-G.B.M. antibodies and may be as high as $40 \%$ in those with anti-G.B.M. nephritis.

Plasmapheresis was carried out on the Aminco continuous-flow blood cell separator (American Instrument Company, Silver Spring, U.S.A.). At each plasmapheresis about four litres of plasma were exchanged for fresh frozen group-compatible plasma. Samples were taken for anti-G.B.M. antibody assay at the beginning and end of each exchange. Using an arteriovenous shunt we found this a simple procedure in which exchange of four to five litres could be achieved within two hours.

\section{Discussion}

The poor prognosis of Goodpasture's syndrome has been emphasized in several studies: 50 of the 52 patients reported before 1964 died, 27 of lung haemorrhage and 23 of renal failure $^{6}$; and of a further 51 cases reported in 197043 died, 21 of renal failure and 20 of lung haemorrhage. ${ }^{7}$ In a more recent study, in which the diagnosis was substantiated by the demonstration of circulating antibody to G.B.M. or elution of this antibody from the diseased kidney, only four out of 32 patients survived with good renal function, and only one of these had had renal failure requiring dialysis. ${ }^{8}$

Previous treatment of Goodpasture's syndrome has usually combined steroids with cytotoxic agents, but since there are no controlled studies conclusions about their value are limited. Growing evidence suggests that the generation of antibody to G.B.M. may be relatively short-lived, at least in some patients with this disease. Levels of anti-G.B.M. antibody can fall after bilateral nephrectomy, and, moreover, an increasing number of patients with Goodpasture's syndrome have been transplanted with no evidence of recurrent glomerular disease in the allotransplanted kidney. ${ }^{8}$ Thus, the therapeutic problem is to tide the patient with Goodpasture's syndrome over the period when the antibodies to basement membrane are being generated. In view of the apparent lack of success with immunosuppressive drugs alone it seemed logical to combine treatment with steroids and cyclophosphamide with the removal of circulating antibody by plasma exchange. The sequential measurement of antibody by radioimmunoassay confirmed the efficacy of plasmapheresis in removing autoantibody, and in our patient improvement in renal function occurred when circulating antibody was no longer detectable.

It was also apparent that antibody levels were falling before plasmapheresis was begun, and that the procedure only hastened removal of antibody from the extracellular fluid, though if the assay result had been immediately available plasma exchange could have been undertaken more often when antibody levels were high. Clearly, further experience is needed to determine whether the combination of plasmapheresis and cytotoxic therapy can maintain an effective reduction of antibody level in patients in the earlier stages of nephrotoxic antibody production.

Studies of glomerular injury by nephrotoxic antibody in animals have emphasized that fixation of antibody in excess of a "threshold" value is required before damage can be detected 
and that above this value there is a good correlation between injury and quantities of antibody administered. ${ }^{910}$ There is thus a rational basis for early and effective reduction in circulating antibody even if complete arrest of antibody synthesis cannot be achieved. Others have argued that continued generation of antibody in patients with Goodpasture's syndrome may be related to the release of glomerular basement antigens from the diseased kidney and have therefore advocated bilateral nephrectomy in patients with uncontrolled pulmonary haemorrhage. ${ }^{11}$ So far the results of this approach have been mixed: in some cases lung haemorrhage has stopped, ${ }^{12} 18$ but in others this procedure has been followed by further pulmonary bleeding. ${ }^{14}$ Intensive plasmapheresis combined with immunosuppressive drugs would certainly seem to be worth considering in any patient with life-threatening lung haemorrhage before submitting him or her to bilateral nephrectomy.

We thank Dr. L. C. Lum of Newmarket Hospital for referring the patient, Dr. D. B. Evans of Addenbrooke's Hospital for performing the renal biopsy, and Dr. D. J. Evans of the Royal Postgraduate Medical School for histological analysis.

\section{Addendum}

We are currently treating a second patient with Goodpasture's syndrome by plasma exchange and immunosuppression.

A 54-year-old man presented in October 1974 with haemoptysis and after a second haemoptysis was admitted to hospital in January 1975. He was found to be anaemic (haemoglobin $8.9 \mathrm{~g} / \mathrm{dl}$ ) with a blood urea of $11 \mathrm{mmol} / \mathrm{l}(66 \mathrm{mg} / 100 \mathrm{ml})$. He was referred to Hammer- smith Hospital on 28 February 1975 with a blood urea of $27 \mathrm{mmol} / 1$ $(162 \mathrm{mg} / 100 \mathrm{ml})$ and a serum creatinine of $522 \mu \mathrm{mol} / 1(5.9 \mathrm{mg} / 100 \mathrm{ml})$. Chest $x$-ray examination showed confluent opacities in the right upper lobe and the sputum contained many siderophages. Renal biopsy showed extensive crescent formation and linear staining for IgG. A blood sample from the January admission showed anti-G.B.M. antibody binding of $4 \%$ which rose to $8 \%$ on samples obtained on 19 February, 28 February, and 3 March. Treatment was started with cyclophosphamide $3 \mathrm{mg} / \mathrm{kg}$, prednisolone $60 \mathrm{mg} /$ day, and plasma exchanges each of about four litres performed five times over nine days. By 12 March 1975 anti-G.B.M. antibodies had fallen to $2 \%$ (normal < $1 \%$ ), serum creatinine to $238 \mu \mathrm{mol} / \mathrm{l}(2 \cdot 7 \mathrm{mg} / 100 \mathrm{ml}$ ), and the chest $x$-ray appearances had returned to normal. Plasmapheresis and immunosuppression are being continued until anti-G.B.M. antibody is no longer detectable.

\section{References}

1 Duncan, D. A., et al., Annals of Internal Medicine, 1965, 62, 920.

2 Lerner, R. A., Glassock, R. J., and Dixon, F. J., Fournal of Experimental Medicine, 1967, 126, 989.

${ }^{3}$ McPhaul, J. J., and Dixon, F. J., fournal of Immunology, 1969, 103, 1168. 4 Evans, D. J., et al., British Medical fournal, 1973, 3, 326.

5 Wilson, C. B., Marquardt, H., and Dixon, F. J., Kidney International, 1974, 6, no. 6, 114A.

6 Benoit, F. L., et al., American fournal of Medicine, 1964, 37, 424

7 Proskey, A. J., et al., American fournal of Medicine, 1970, 48, 62.

8 Wilson, C. B., and Dixon, F. J., Kidney International, 1973, 3, 74.

Henson, P. M., and Cochrane, C. G., Progress in Immunology, ed. B. Amos, p. 157. New York, Academic Press, 1972.

10 Simpson, I. J., et al., Clinical and Experimental Immunology, in press.

11 Seigel, R. R., American Fournal of Medical Science, 1970, 259, 201.

12 Maddock, R. K., et al., Annals of Internal Medicine, 1967, 67, 1258.

13 Nowakowski, A., et al., Annals of Internal Medicine, 1971, 75, 243.

14 Eisinger, A. J., American fournal of Medicine, 1973, 55, 565.

\section{SHORT REPORTS}

\section{Epigastric Pain in Duodenal Ulcer}

Some investigators have thought that pain in duodenal ulceration is due to the direct effect of acid on the ulcer. ${ }^{1}$ Others have claimed that mobility of the gastroduodenal region is disturbed during pain. ${ }^{2}$ Nevertheless, when muscular activity of the gastroduodenal region was abolished without affecting the acidity, ulcer pain was not relieved. ${ }^{3}$ Earlam has suggested that the pain arises from hypersensitivity of the lower oesophageal mucosa to acid. ${ }^{4}$ To test this hypothesis we have studied the gastro-oesophageal junction in $\mathbf{4 4}$ patients with proved duodenal ulceration.

\section{Patients, Methods, and Results}

Thirty-seven of 44 patients with radiologically and endoscopically proved duodenal ulcer (group A) had central epigastric pain, below the xiphisternum in the midline between the costal margins, and seven (group B) had nonepigastric pain. In all patients the function of the gastro-oesophageal junction was assessed by oesophageal manometry; acid infusion test; and radiography. Informed consent was obtained from all patients. Patients in group A had a mean pressure of $13.1 \mathrm{~mm} \pm 5 \cdot 6$ S.D., while those in group B had a mean of $13.0 \mathrm{~mm} \pm 4.04 \mathrm{~S}$.D. (see fig.). During the acid infusion 12 experienced only retrosternal pain-nine in group $A$ and three in group B. Another 12 complained of their usual epigastric pain and three of these experienced retrosternal pain. Any pain was abolished by $2.4 \%$ bicarbonate infusion of the oesophagus, but when $0.1 \mathrm{~N} \mathrm{HCl}$ was reinfused the pain always returned. In four of the 12 patients in whom acid infusion caused epigastric pain $200 \mathrm{ml}$ of $2.4 \%$ bicarbonate solution was instilled into the stomach. When acid was reinfused into the oesophagus the epigastric pain did not recur despite the infusion continuing for 30 minutes. The remaining 20 patients (16 in group $A$ and four in group $B$ ) did not experience any pain during the acid infusion.

Nine patients in group $A$ and two in group $B$ had a relevant radiological abnormality of the gastro-oesophageal junction.

\section{Discussion}

Earlam reproduced the epigastric pain of duodenal ulcer by infusing acid into the oesophagus in 53 of his 61 patients complaining of epigastric pain compared with none of his 39 patients complaining of nonepigastric pain." We reproduced the epigastric pain in 12 of 37

patients complaining of epigastric pain. Apart from four patients no precautions were taken to prevent the infused acid from reaching the duodenal ulcer, so that some of the pain may have resulted from stimulation of the ulcer rather than of the oesophageal mucosa. Nevertheless, in four patients the epigastric pain which developed during the acid infusion was abolished when the stomach was neutralized with bicarbonate solution. This agrees with a report that a positive result from an acid perfusion test is more likely to occur in the presence of gastritis. ${ }^{5}$

The pain may have been mediated by the oesophageal mucosa, but in 25 of our group A patients we could not reproduce the pain by exposing the oesophageal mucosa to $\mathrm{pH} 1$ for 30 minutes. But 12 of those with epigastric pain felt retrosternal pain during the acid 